\title{
Recipientes e substratos na germinação e desenvolvimento de crisântemo e amor-perfeito ${ }^{(1)}$
}

\author{
KELLI PIROLA(2), MARCELO DOTTO(2), AMÉRICO WAGNER JUNIOR ${ }^{(3)}$, \\ ALEXANDRE LUIS ALEGRETT|(3), PAULO CÉSAR CONCEIÇÃO( ${ }^{(3)}$ e ANGÉLICA SIGNOR MENDES ${ }^{(3)}$
}

\begin{abstract}
RESUMO
O objetivo deste trabalho foi avaliar o efeito do substrato e tamanho de recipiente na germinação e desenvolvimento de crisântemo e amor-perfeito. Os trabalhos foram realizados no Viveiro de Produção de Mudas Hortícolas da UTFPR Campus Dois Vizinhos-PR. O delineamento experimental adotado foi em blocos casualizados, em fatorial 3 x 4 (tamanho de recipiente x substrato), com quatro repetições, considerando-se 4 recipientes como unidade experimental. Foram usados como recipientes os tubetes pequenos, médios e grandes e como substratos, Plantmax ${ }^{\circledR}$ e as misturas, Latossolo Vermelho + Areia + Cama de Frango 1 (1:1:1 v/v), Latossolo Vermelho + Areia + Cama de Frango 2 (1:1:1 v/v) e Latossolo Vermelho + Areia + Cama de Frango $1+$ Cama de frango 2 (1:1:1:1 v/v). As camas de Frango 1 e 2 foram compostas por maravalha e serragem, respectivamente. Foram avaliadas 63 dias após a instalação do experimento a germinação(\%), comprimento total das plantas $(\mathrm{cm})$, comprimento das raízes $(\mathrm{cm})$, altura $(\mathrm{cm})$, número de folhas e a massa da matéria seca das plantas $(\mathrm{g})$. Para germinação e desenvolvimento inicial de amor-perfeito o melhor recipiente foi o pequeno com a mistura Latossolo Vermelho + Areia + Cama de Frango 1 + Cama de frango 2 (1:1:1:1 v/v). Para crisântemo além deste recipiente e mistura, também se destacaram as misturas Latossolo Vermelho + Areia + Cama de Frango 1 (1:1:1 v/v) e Latossolo Vermelho + Areia + Cama de Frango $2(1: 1: 1 \mathrm{v} / \mathrm{v})$.
\end{abstract}

Palavras-chave: Dendrathema grandiflora, propagação sexuada, planta ornamental.

\begin{abstract}
Recipients and substrate for germination and growth of chrysanthemum and "Viola $x$ wittrockiana" plants The aim of this work was to evaluate the substrate effect and recipient size on the germination and initial growth of chrysanthemum and perfect-love ornamental plants. The works was carried out in the Horticulture Nursery from UTFPR Campus Dois Vizinhos - Paraná State, Brazil. The experimental design was in blocks randomized, in factorial 3 x 4 (recipient size $\mathrm{x}$ substrate), with four replications, considering 4 recipients by plot. It was used as recipients, small, medium and king container and as substrate the Plantmax ${ }^{\circledR}$ and the mixture Red Latosoil + Sand + Poultry Litter 1 (1:1:1 v/v), Red Latosoil + Sand + Poultry Litter $2(1: 1: 1 \mathrm{v} / \mathrm{v})$ and Red Latosoil + Sand + Poultry Litter $1+$ Poultry Litter 2 (1:1:1:1 v/v). The Poultry Litter 1 and 2 had wood shavings and sawdust as different ingredients, respectively. The germination (\%), total lenght plants $(\mathrm{cm})$, roots length $(\mathrm{cm})$, height $(\mathrm{cm})$, leaf number and plants dry mass matter $(\mathrm{g})$, were evaluate 63 days after experiment installation. For germination and early development of perfect-love the best container was small with a mixture the red latosoil + sand + Poultry Litter $1+$ Poultry Litter $2(1: 1: 1: 1 \mathrm{v} / \mathrm{v})$. For Chrysanthemum, besides to this container and mixing, the mixtures were also important Red Latosoil + sand + Poultry Litter $1(1: 1: 1 \mathrm{v} / \mathrm{v})$ e Red Latosoil + sand + Poultry Litter 2 (1:1:1 v/v).

Keywords: Dendrathema grandiflora, sexual propagation, ornamental plants.
\end{abstract}

\section{INTRODUÇÃO}

A produção e o consumo de flores e plantas ornamentais no Brasil estão acompanhando a tendência de crescimento do mercado mundial, ampliando-se a cada ano. Avalia-se que a floricultura brasileira movimente, no mercado doméstico, valor global, em torno de 750 milhões de dólares ao ano. Embora não seja exportador tradicional de flores e plantas ornamentais, a profissionalização do segmento exportador no Brasil está se intensificando nos últimos anos e, hoje, o país já se projeta no cenário internacional como importante referencial de qualidade e competitividade (JUNQUEIRA e PEETZ, 2002).
Conforme Demarchi (2001), apesar das rosas, cravos e cravinas ainda representarem em torno de $70 \%$ da demanda mundial, as flores tropicais também vem ganhando espaço nesse mercado, como é o caso de orquídeas, antúrios, bromélias, alpínias, musáceas e helicônias.

A quantidade de crisântemos comercializados no Brasil está acompanhando este crescimento contínuo de mercado, sendo considerada a primeira flor de corte em volume de produção (CHAGAS et al., 2006). Entre os vários fatores responsáveis pelo sucesso do cultivo de crisântemo no país, pode-se citar a escolha de bons genótipos, o manejo cultural e fitossanitário e a adubação, tudo isso, partindo-se inicialmente da obtenção de mudas de boa qualidade fisiológica e sanitária.

(1) Trabalho recebido para publicação em 26/10/2012 e aprovado em 01/06/2015

(2) Universidade Tecnológica Federal do Paraná (UTFPR) - Campus Pato Branco, Pato Branco-PR, Brasil. *Autor correspondente: kelli_pirola1@ hotmail.com

(3) Universidade Tecnológica Federal do Paraná (UTFPR) - Campus Dois Vizinhos, Dois Vizinhos-PR, Brasil. 
O amor-perfeito (Viola $x$ wittrockiana), apesar de ser planta ornamental perene, é cultivado como anual, com potencialidades para uso no paisagismo, com maior adaptação a regiões mais frias, como no sul do país. Tradicionalmente, seu cultivo se dá densamente a meiasombra, sendo sua propagação realizada por sementes (PILLA et al., 2006).

Todavia, na produção de mudas de qualquer espécie ornamental, o viveirista busca sempre reduzir o tempo para sua comercialização, aliado à redução do custo para obtêla, mantendo a qualidade necessária, conforme exigência do mercado (CARVALHO et al., 2000).

Neste sentido, o êxito na produção de mudas por sementes, de qualquer cultura, depende de vários fatores, entre os quais está na utilização de sementes de boa qualidade e nas escolhas do melhor substrato e recipiente. Estes fatores exercem influência sobre a emergência de plântulas e na formação de mudas de boa qualidade (WAGNER JÚNIOR et al., 2006a).

Inúmeros materiais podem ser empregados como recipiente e substrato. Porém, deve-se levar em conta a disponibilidade e custo de ambos juntamente, com as características físico-químicas do substrato (NICOLOSO et al., 2000) e que os recipientes sejam atóxicos.

Atualmente, existe ampla gama de sistemas de cultivo de mudas floríferas em recipientes. Tais sistemas utilizam substratos de origem mineral ou orgânica, natural ou sintética, cujas características diferem marcadamente das do solo (GUERRERO e POLO, 1989), não existindo um material ou mistura de materiais considerada válida como substrato para todas as espécies e recipientes (WAGNER JÚNIOR et al., 2006b).

Quanto à escolha do substrato, é difícil encontrar aquele que, sozinho atenda a todas as exigências da planta a ser cultivada. Isso leva à formulação de misturas nas quais se tenta obter inúmeras características desejáveis para produção de mudas (WAGNER JÚNIOR et al., 2006b).

Normalmente, o uso na mistura com alguns materiais orgânicos ao substrato favorece na melhoria das características químicas, físicas e biológicas, de modo a criar ambiente mais adequado para o desenvolvimento das raízes e da planta como todo (CASA GRANDE JÚNIOR et al., 1996).

Segundo Pasqual et al. (2001), mesmo que um substrato possa não reunir todas as qualidades necessárias para produção de mudas de qualidade, deve-se selecionar aquele que reuna as melhores características, sendo estreitamente relacionado à eficiência do sistema de propagação e da viabilidade de uso de recipientes. Para isso, torna-se necessário a realização de estudos que demonstrem qual melhor tipo de substrato e recipiente, na produção de mudas de crisântemo e amor-perfeito, espécies ornamentais de grande importância no mercado.

O objetivo deste trabalho foi avaliar substratos e tamanho de recipiente na germinação e desenvolvimento de crisântemo e amor-perfeito.

\section{MATERIAL E MÉTODOS}

O trabalho foi realizado no viveiro de produção de mudas da Estação Experimental da UTFPR, Campus Dois Vizinhos-PR. Foram utilizadas sementes comerciais de crisântemo (Dendrathema grandiflora Tzelev.) e de amorperfeito (Viola $x$ wittrockiana Gams.). As sementes foram semeadas duas por recipiente, em profundidade de $0,5 \mathrm{~cm}$. Foram usados como recipientes tubetes pequenos redondos ( 12 x 2,5 cm - 6 estrias), médios redondos (14,5 x 3,5 cm 8 estrias) e grandes redondos ( $20 \times 5 \mathrm{~cm}-8$ estrias).

Quatro tipos de substratos foram utilizados, sendo estes, Plantmax ${ }^{\circledR}(\mathrm{S} 1)$, Latossolo Vermelho + Areia + Cama de Frango 1 (1:1:1 v/v) (S2), Latossolo Vermelho + Areia + Cama de Frango 2 (1:1:1 v/v) (S3) e Latossolo Vermelho + Areia + Cama de Frango 1 + Cama de Frango 2 (1:1:1:1 v/v) (S4). As Camas de Frango 1 e 2 diferiram quanto a sua composição, sendo estas compostas por maravalha de Pinus sp. e serragem, respectivamente. Para compor as misturas dos substratos, estes foram homogeneizados com auxílio de uma betoneira de 400 litros. As características químicas e físicas dos substratos foram apresentadas nas Tabelas 1 e 2, respectivamente.

Tabela 1. Caracterização química dos quatro substratos utilizados na germinação e desenvolvimento de plantas de amorperfeito e Crisântemo.

Table 1. Chemical characterization from four substrates use for germination and growth of perfect-love and chrysanthemum.

\begin{tabular}{|c|c|c|c|c|c|c|c|c|c|c|c|c|}
\hline \multirow{2}{*}{ Substrato } & $\mathrm{pH}$ & $\mathrm{P}$ & $\mathrm{K}$ & $\mathrm{Ca}^{2+}$ & \multicolumn{2}{c|}{$\mathrm{Mg}^{2+}$} & $\mathrm{Al}^{3+}$ & $\mathrm{H}+\mathrm{Al}$ & $\mathrm{SB}$ & $\mathrm{CTC}$ & $\mathrm{V}$ & $\mathrm{MO}$ \\
\hline & $\mathrm{H}_{2} \mathrm{O}$ & \multicolumn{2}{|c|}{$\mathrm{mg} \mathrm{dm}^{-3}$} & \multicolumn{5}{|c|}{$\mathrm{cmolc} \mathrm{dm}^{-3}$} \\
\hline $\mathrm{S}^{\mathrm{a}}$ & $5,47^{\mathrm{b}}$ & $662,1^{\mathrm{b}}$ & $600^{\mathrm{b}}$ & $9,64^{\mathrm{b}}$ & $3,95^{\mathrm{b}}$ & $0,0^{\mathrm{b}}$ & $6,9^{\mathrm{b}}$ & $15,12^{\mathrm{b}}$ & $15,12^{\mathrm{b}}$ & $68,7^{\mathrm{b}}$ & $\mathrm{g} \mathrm{dm}^{-3}$ \\
\hline $\mathrm{S}^{\mathrm{a}}$ & 6,10 & 106,3 & 782,00 & 3,24 & 2,54 & 0,0 & 2,36 & 7,78 & 10,14 & 76,73 & 16,08 \\
\hline $\mathrm{S}^{\mathrm{a}}$ & 6,00 & 324,99 & 782,00 & 3,15 & 2,84 & 0,0 & 2,19 & 7,99 & 10,18 & 78,49 & 44,23 \\
\hline $\mathrm{S}^{\mathrm{a}}$ & 6,40 & 420,97 & $1.036,2$ & 3,44 & 3,45 & 0,0 & 1,90 & 9,54 & 11,44 & 83,39 & 57,63 \\
\hline
\end{tabular}

${ }^{\mathrm{a}}(\mathrm{S} 1)$ Plantmax $^{\circledR}$, (S2) Latossolo Vermelho + Areia + Cama de Frango 1 (1:1:1 v/v), (S3) Latossolo Vermelho + Areia + Cama de Frango 2 (1:1:1 v/v), (S4) Latossolo Vermelho + Areia + Cama de Frango $1+$ Cama de Frango 2 (1:1:1:1 v/v).

${ }^{b} \mathrm{pH}$ em água, $\mathrm{KCl}$ e $\mathrm{CaCl}_{2}$ - Relação 1:2,5; P, Na, K, Fe, Zn, Mn e Cu - Extrator Mehlich 1; Ca, Mg, Al - Extrator: $\mathrm{KCl} 1 \mathrm{molL}^{-1} ; \mathrm{H}+\mathrm{Al}-\mathrm{Extrator}$ Acetato de Cálcio 0,5 molL-1 pH 7,0; B - Extrator água quente; $\mathrm{S}$ - Extrator fosfato monocálcio em ácido acético; $\mathrm{SB}=\mathrm{Soma}$ de Bases; CTC = Capacidade de Troca Catiônica; $\mathrm{V}$ = Índice de Saturação de bases. 
Tabela 2. Características físicas dos substratos contendo cama de aves composta por serragem (Amostra 1) e composta com maravalha (Amostra 2) utilizados na germinação e desenvolvimento de plantas de amor-perfeito e crisântemo.

Table 2. Physical characteristics of substrates containing chicken litter composed of sawdust (Sample 1) and composed with shavings (Sample 2) used in germination and growth of perfect-love and chrysanthemum.

\begin{tabular}{|c|c|c|c|c|c|c|c|}
\hline Material & DS (g/cm $\left.{ }^{3}\right)$ & $\operatorname{VPt}(\%)$ & Microporos & Macroporos & Areia (\%) & Argila (\%) & Silte (\%) \\
\hline Amostra $1^{\mathrm{a}}$ & $1,40^{\mathrm{b}}$ & $48,02^{\mathrm{b}}$ & 28,66 & 19,36 & 46,93 & 34,70 & 18,37 \\
\hline Amostra $2^{\mathrm{a}}$ & 1,41 & 50,52 & 35,69 & 14,83 & 46,69 & 42,82 & 10,49 \\
\hline
\end{tabular}

${ }^{a}$ Amostra 1: Substrato composto por Latossolo Vermelho + Areia + Cama de Frango composta por serragem (1:1:1 v/v); Amostra 2: Latossolo Vermelho

+ Areia + Cama de Frango composta por maravalha $(1: 1: 1 \mathrm{v} / \mathrm{v})$.

${ }^{\mathrm{b}} \mathrm{DS}\left(\mathrm{g} / \mathrm{cm}^{3}\right)$ : Densidade; VPt (\%): Porosidade total.

Após a germinação, as plantas foram desbastadas, deixando-se apenas a mais vigorosa por recipiente plástico. A irrigação foi ministrada diariamente, com maior frequência nos primeiros dias após a semeadura. A temperatura média foi de $23,19 \pm 0,81^{\circ} \mathrm{C}$.

$\mathrm{O}$ delineamento experimental adotado foi em blocos casualizados, em fatorial $3 \times 4$ (tamanho de recipiente $\mathrm{x}$ substrato), com quatro repetições, considerando-se como unidade experimental, cada lote de 4 recipientes.

As avaliações foram realizadas 63 dias após a instalação do experimento. As variáveis analisadas foram germinação(\%), comprimento total das plantas $(\mathrm{cm})$, comprimento das raízes $(\mathrm{cm})$, altura $(\mathrm{cm})$, número de folhas e a massa da matéria seca das plantas(g). Os dados foram submetidos à análise de variância e ao teste de Tukey ( $p$ $<0,05)$, por meio do programa computacional SANEST (ZONTA e MACHADO, 1984). Os dados das porcentagens de germinação foram transformados segundo arco seno $\sqrt{x / 100}$, segundo necessidade apresentada pelo teste de normalidade de Lilliefors. Já os demais dados não sofreram transformação. Para determinação do comprimento total das plantas, as mesmas foram retiradas dos substratos, cuidadosamente, lavadas em água e medidas com auxílio de régua graduada em centímetros. Posteriormente, para obtenção da massa da matéria seca, as plantas foram colocadas em envelopes de papel e transferidas para estufa com circulação de ar a $60^{\circ} \mathrm{C}$, permanecendo por 72 horas até atingirem peso constante.

\section{RESULTADOS E DISCUSSÃO}

\section{Amor-perfeito}

A interação, tamanho de recipiente x substrato, não foi significativa apenas para variável altura das plantas de amor-perfeito.

Pelos resultados obtidos na Tabela 3, verificou-se que nos substratos S1, S2 e S3 não houve diferença entre as médias de germinação dentro dos três tipos de recipientes testados. Entretanto, no substrato S4, a maior média foi obtida com recipiente pequeno, atingindo-se $100 \%$ de germinação, sendo não diferente estatisticamente do tamanho médio (72,98\%) (Tabela 3). Esta resposta de superioridade com menor recipiente é favorável para o viveirista, uma vez que com menor volume de substrato possibilita-se máxima germinação, reduzindo no custo final da produção da muda.

Tabela 3. Germinação de sementes (\%), de amor-perfeito de acordo com o tamanho de recipiente e o substrato utilizado. Table 3. Seeds germination (\%) of perfect-love ornamental plant according to recipients size and substrate.

\begin{tabular}{|c|c|c|c|}
\hline \multirow{2}{*}{ Substrato } & \multicolumn{3}{|c|}{ Tamanho de recipiente } \\
\hline & Pequeno & Médio & Grande \\
\hline $\mathrm{S} 1^{\mathrm{a}}$ & $50,25 \mathrm{~b} \mathrm{~A}^{1}$ & 97,65 a A & 97,65 a A \\
\hline $\mathrm{S} 2^{\mathrm{a}}$ & $41,54 \mathrm{~b} \mathrm{~A}$ & 49,99 a A & 80,16 a $A$ \\
\hline $\mathrm{S} 3^{\mathrm{a}}$ & $97,65 \mathrm{ab} A$ & 90,82 a A & 97,65 a $\mathrm{A}$ \\
\hline $\mathrm{S} 4^{\mathrm{a}}$ & 100,00 a $\mathrm{A}$ & 72,98 a $\mathrm{AB}$ & 58,70 a B \\
\hline $\mathrm{CV}(\%)$ & \multicolumn{3}{|c|}{33,80} \\
\hline
\end{tabular}

${ }^{\mathrm{a}}(\mathrm{S} 1)$ Plantmax $^{\circledR}$, (S2) Latossolo Vermelho + Areia + Cama de Frango 1 (1:1:1 v/v), (S3) Latossolo Vermelho + Areia + Cama de Frango 2 (1:1:1 v/v), (S4) Latossolo Vermelho + Areia + Cama de Frango $1+$ Cama de Frango 2 (1:1:1:1 v/v).

${ }^{1}$ Médias com letras diferentes, minúscula na mesma coluna e maiúsculas na mesma linha, diferem significativamente ao nível de $5 \%$ de probabilidade pelo teste de Tukey. 
Segundo Kämpf (2000), o tipo de recipiente pode influenciar nas características físicas do substrato, sendo que, quanto menor a altura do recipiente, mais difícil poderá ser a drenagem do substrato. Neste sentido, acredita-se que, a superioridade do recipiente pequeno e médio possa estar relacionada às características físicas do substrato $\mathrm{S} 4$, proporcionando menor perda de água mesmo em recipiente pequeno.

Nos substratos S3 e S4, havia em sua composição a serragem, o que pode ter favorecido para maior retenção de água, devidos às características físicas deste material (Tabela 2) (menor diâmetro de partícula que a maravalha).
Segundo Carrijo et al. (2004), a serragem está entre os substratos que retém mais água na faixa de 1 a $5 \mathrm{kPa}$ (água facilmente disponível) quando comparado com a fibra de coco, casca de arroz carbonizada, maravalha e lã de rocha.

Em relação ao comprimento total e massa de matéria seca das plantas (Tabelas 4 e 5, respectivamente), observouse que não há diferenças estatísticas entre as médias, quando se compararam os quatro substratos nos recipientes de tamanho médio e grande. Já dentro do recipiente pequeno, não houve diferenças entre os substratos S4, S3 e S2 para o comprimento total (Tabela 4) e, S4, S3 e S1 para a massa da matéria seca das plantas (Tabela 5).

Tabela 4. Comprimento total $(\mathrm{cm})$ de plantas de amor-perfeito de acordo com o tamanho de recipiente e o substrato utilizado.

Table 4. Total length $(\mathrm{cm})$ of perfect-love ornamental plant according to recipients size and substrate.

\begin{tabular}{|c|c|c|c|}
\hline \multirow{2}{*}{ Substrato } & \multicolumn{3}{|c|}{ Tamanho de recipiente } \\
\hline & Pequeno & Médio & Grande \\
\hline $\mathrm{S} 1^{\mathrm{a}}$ & $8,55 \mathrm{~b} \mathrm{~B}^{1}$ & 18,00 a $\mathrm{A}$ & 23,07 a $\mathrm{A}$ \\
\hline $\mathrm{S} 2^{\mathrm{a}}$ & $14,38 \mathrm{ab} \mathrm{A}$ & 16,06 a $\mathrm{A}$ & 14,26 a $\mathrm{A}$ \\
\hline $\mathrm{S} 3^{\mathrm{a}}$ & $13,21 \mathrm{ab} A$ & 16,81 a $\mathrm{A}$ & 18,83 a $\mathrm{A}$ \\
\hline $\mathrm{S} 4^{\mathrm{a}}$ & 21,03 a A & 14,17 a $\mathrm{A}$ & 17,34 a $\mathrm{A}$ \\
\hline CV $(\%)$ & \multicolumn{3}{|c|}{32,05} \\
\hline
\end{tabular}

${ }^{\mathrm{a}}(\mathrm{S} 1)$ Plantmax $^{\circledR},(\mathrm{S} 2)$ Latossolo Vermelho + Areia + Cama de Frango $1(1: 1: 1 \mathrm{v} / \mathrm{v}),(\mathrm{S} 3)$ Latossolo Vermelho + Areia + Cama de Frango $2(1: 1: 1 \mathrm{v} / \mathrm{v})$, (S4) Latossolo Vermelho + Areia + Cama de Frango $1+$ Cama de Frango $2(1: 1: 1: 1 \mathrm{v} / \mathrm{v})$.

${ }^{1}$ Médias com letras diferentes, minúscula na mesma coluna e maiúsculas na mesma linha, diferem significativamente ao nível de 5\% de probabilidade pelo teste de Tukey.

Tabela 5. Massa de matéria seca (g) de plantas de amor-perfeito de acordo com o tamanho de recipiente e o substrato utilizado.

Table 5. Mass dry matter (g) of perfect-love ornamental plant according to recipients size and substrate.

\begin{tabular}{|c|c|c|c|}
\hline \multirow{2}{*}{ Substrato } & \multicolumn{3}{|c|}{ Tamanho de recipiente } \\
\hline & Pequeno & Médio & Grande \\
\hline $\mathrm{S} 1^{\mathrm{a}}$ & $0,17 \mathrm{ab} \mathrm{A}$ & 0,26 a $\mathrm{A}$ & 0,23 a $A$ \\
\hline $\mathrm{S} 2^{\mathrm{a}}$ & 0,12 b A & 0,13 a $A$ & 0,18 a $\mathrm{A}$ \\
\hline $\mathrm{S} 3^{\mathrm{a}}$ & $0,18 \mathrm{ab} A$ & 0,20 a $\mathrm{A}$ & 0,19 a $\mathrm{A}$ \\
\hline $\mathrm{S} 4^{\mathrm{a}}$ & 0,41 a $\mathrm{A}$ & 0,07 a $B$ & 0,10 a $B$ \\
\hline CV $(\%)$ & \multicolumn{3}{|c|}{71,20} \\
\hline
\end{tabular}

${ }^{\mathrm{a}}$ (S1) Plantmax ${ }^{\circledR}$, (S2) Latossolo Vermelho + Areia + Cama de Frango 1 (1:1:1 v/v), (S3) Latossolo Vermelho + Areia + Cama de Frango 2 (1:1:1 v/v), (S4) Latossolo Vermelho + Areia + Cama de Frango $1+$ Cama de Frango 2 (1:1:1:1 v/v).

${ }^{1}$ Médias com letras diferentes, minúscula na mesma coluna e maiúsculas na mesma linha, diferem significativamente ao nível de $5 \%$ de probabilidade pelo teste de Tukey.

Como o crescimento da parte aérea das plantas não se diferenciaram estatisticamente entre si, suspeita-se que o maior comprimento total das plantas obtido no S4, S3 e S2 (Tabela 4) possam estar ligados ao uso de cama de frango na composição destes, aumentando-se o $\mathrm{pH}$ dos mesmos para valores considerados altos para substratos, o que prejudica a absorção dos micronutrientes (KÄMPF,
2000). Com isso, uma das estratégias que a planta possa ter utilizado foi de alongar o crescimento radicular, buscandose alguma área em que fosse possível absorver estes nutrientes. Segundo Taiz e Zeiger (2004), a habilidade das plantas em obter nutrientes minerais está relacionada à sua capacidade de desenvolver extenso sistema radicular, o que fez tal suposição no presente trabalho. 
Nos substratos S2, S3 e S4, as médias do comprimento total das plantas, nos três recipientes não diferiram estatisticamente entre si (Tabela 4). Contudo, no substrato S1, o maior comprimento total das plantas foi obtido com o recipiente grande, sendo este semelhante estatisticamente do tamanho médio. $\mathrm{O}$ mesmo resultado foi obtido para o comprimento de raízes.

Segundo Bezerra (2003), recipientes maiores permitem maior volume de raízes, aumentando a área de absorção de nutrientes. Por isso, um dos fatores que influenciaram para o maior crescimento das raízes (Tabela 7), nos recipientes de maior tamanho, está relacionado ao maior volume permitido para o crescimento radicular em extensão, proporcionando consequentemente o maior comprimento total das plantas (Tabela 4).

Além disso, Francisco et al. (2010), descreveram que o recipiente menor demanda menor quantidade de substrato, com isso ocorre redução na disponibilidade de nutrientes. Assim, pelo fato destes substratos possuírem menor quantidade de macronutrientes, se comparado ao S1 (Tabela 1), houve maior crescimento radicular, já que as raízes tiveram que buscar os nutrientes necessários para seu desenvolvimento.

Quanto ao número de folhas foi observado que, o substrato S4 utilizando recipiente pequeno apresentou maior média, podendo estar relacionado com a maior quantidade de potássio presente no mesmo. O potássio é um macronutriente que tem papel fundamental no metabolismo vegetal, atuando como ativador de enzimas (MATTOS E MONTEIRO, 1998), o que pode ter contribuído para maior obtenção de folhas, conforme descrito por Guardia e Benlloch (1980). Por outro lado, no recipiente grande as maiores médias foram com os substratos S1, S2 e S3, fato que pode estar ligado a maior quantidade de substrato disponível no mesmo (Tabela 6).

Tabela 6. Número de folhas, de plantas de amor-perfeito de acordo com o tamanho de recipiente e o substrato utilizado. Table 6. Leaf number of perfect-love ornamental plant according to recipients size and substrate.

\begin{tabular}{|c|c|c|c|}
\hline \multirow{2}{*}{ Substrato } & \multicolumn{3}{|c|}{ Tamanho de recipiente } \\
\cline { 2 - 4 } & Pequeno & Médio & Grande \\
\hline S1 $^{\mathrm{a}}$ & $2,48 \mathrm{~b} \mathrm{~B}^{1}$ & $9,24 \mathrm{a} \mathrm{A}$ & $14,09 \mathrm{a} \mathrm{A}$ \\
\hline S2 $^{\mathrm{a}}$ & $5,48 \mathrm{~b} \mathrm{~A}$ & $6,73 \mathrm{a} \mathrm{A}$ & $8,96 \mathrm{ab} \mathrm{A}$ \\
\hline S3 $^{\mathrm{a}}$ & $6,33 \mathrm{~b} \mathrm{~A}$ & $8,20 \mathrm{a} \mathrm{A}$ & $6,38 \mathrm{ab} \mathrm{A}$ \\
\hline S4 & a & $14,35 \mathrm{a} \mathrm{A}$ & $5,80 \mathrm{a} \mathrm{B}$ \\
\hline
\end{tabular}

${ }^{a}(\mathrm{~S} 1)$ Plantmax $^{\circledR},(\mathrm{S} 2)$ Latossolo Vermelho + Areia + Cama de Frango 1 (1:1:1 v/v), (S3) Latossolo Vermelho + Areia + Cama de Frango 2 (1:1:1 v/v), (S4) Latossolo Vermelho + Areia + Cama de Frango $1+$ Cama de Frango 2 (1:1:1:1 v/v).

${ }^{1}$ Médias com letras diferentes, minúscula na mesma coluna e maiúsculas na mesma linha, diferem significativamente ao nível de 5\% de probabilidade pelo teste de Tukey.

Tabela 7. Comprimento de raízes $(\mathrm{cm})$ de plantas de amor-perfeito de acordo com o tamanho de recipiente e o substrato utilizado.

Table 7. Root length $(\mathrm{cm})$ of perfect-love ornamental plant according to recipients size and substrate.

\begin{tabular}{|c|c|c|c|}
\hline \multirow{2}{*}{ Substrato } & \multicolumn{3}{|c|}{ Tamanho de recipiente } \\
\hline S1 ${ }^{\mathrm{a}}$ & Pequeno & Médio & Grande \\
\hline $\mathrm{S}^{\mathrm{a}}{ }^{\mathrm{a}}$ & $7,30 \mathrm{~b} \mathrm{~B}^{1}$ & $14,90 \mathrm{a} \mathrm{A}$ & $18,85 \mathrm{a} \mathrm{A}$ \\
\hline $\mathrm{S}^{\mathrm{a}}$ & $11,49 \mathrm{ab} \mathrm{A}$ & $13,50 \mathrm{a} \mathrm{A}$ & $12,43 \mathrm{a} \mathrm{A}$ \\
\hline $\mathrm{S}^{\mathrm{a}}{ }^{\mathrm{a}}$ & $11,62 \mathrm{ab} \mathrm{A}$ & $13,60 \mathrm{a} \mathrm{A}$ & $14,98 \mathrm{a} \mathrm{A}$ \\
\hline $\mathrm{CV}(\%)$ & $18,01 \mathrm{a} \mathrm{A}$ & $12,57 \mathrm{a} \mathrm{A}$ & $13,54 \mathrm{a} \mathrm{A}$ \\
\hline
\end{tabular}

${ }^{\mathrm{a}}(\mathrm{S} 1)$ Plantmax $^{\circledR}$, (S2) Latossolo Vermelho + Areia + Cama de Frango 1 (1:1:1 v/v), (S3) Latossolo Vermelho + Areia + Cama de Frango 2 (1:1:1 v/v), (S4) Latossolo Vermelho + Areia + Cama de Frango $1+$ Cama de Frango 2 (1:1:1:1 v/v).

${ }^{1}$ Médias com letras diferentes, minúscula na mesma coluna e maiúsculas na mesma linha, diferem significativamente ao nível de 5\% de probabilidade pelo teste de Tukey.

Serrano (2006) citou que o maior volume do substrato permitiu maior desenvolvimento das raízes, possibilitando maior exploração e absorção de nutrientes, o que favoreceu para número de folhas.

\section{Crisântemo}

A germinação de sementes de crisântemo mostrou-se significativa apenas dentro do fator substrato (Tabela 8), sendo que o mesmo comportamento estatístico não foi observado no fator recipiente e na interação recipiente $\mathrm{x}$ substrato.

Porém, para as variáveis comprimento total, massa de matéria seca, número de folhas, comprimento de raízes e altura, a interação tamanho de recipiente $\mathrm{x}$ substrato foi estatisticamente significativa (Tabelas 9 a 13). 
Tabela 8. Germinação de sementes (\%) de crisântemo de acordo com o substrato utilizado.

Table 8. Seeds germination (\%) of chrysanthemum plant according to recipients size and substrate.

\begin{tabular}{|c|c|}
\hline Substrato & Germinação (\%) \\
\hline $\mathrm{S} 1^{\mathrm{a}}$ & $93,56 \mathrm{~b}$ \\
\hline $\mathrm{S} 2^{\mathrm{a}}$ & $99,74 \mathrm{ab}$ \\
\hline $\mathrm{S} 3^{\mathrm{a}}$ & $100,0 \mathrm{a}$ \\
\hline $\mathrm{S} 4^{\mathrm{a}}$ & $97,65 \mathrm{ab}$ \\
\hline CV (\%) & 14,76 \\
\hline
\end{tabular}

${ }^{a}(\mathrm{~S} 1)$ Plantmax $^{\circledR}$, (S2) Latossolo Vermelho + Areia + Cama de Frango 1 (1:1:1 v/v), (S3) Latossolo Vermelho + Areia + Cama de Frango 2 (1:1:1 $\mathrm{v} / \mathrm{v})$, (S4) Latossolo Vermelho + Areia + Cama de Frango $1+$ Cama de Frango $2(1: 1: 1: 1 \mathrm{v} / \mathrm{v})$.

${ }^{1}$ Médias com letras diferentes, minúscula na mesma coluna diferem significativamente ao nível de 5\% de probabilidade pelo teste de Tukey.
Para germinação, a maior média foi obtida com o substrato $\mathrm{S} 3$, que não diferiu estatisticamente das misturas S2 e S4 (Tabela 8). Observou-se que nestes substratos existe em sua composição a presença de cama de aviário, podendo este material ter melhorado as características físicas dos mesmos, permitindo maior aeração e retenção de água, necessárias para ativar o processo germinativo das sementes. Segundo Luz et al. (2009), a cama de frango é uma boa fonte de nutrientes, especialmente de nitrogênio, o seu uso adiciona matéria orgânica que melhora os atributos físicos do solo, aumenta a capacidade de retenção de água e melhora a aeração.

Segundo Wagner Júnior et al. (2007), substratos que contém adequada quantidade de matéria orgânica apresentam boa capacidade de retenção de água e aeração, além de alta quantidade de nutrientes disponíveis para a planta.

Tabela 9. Comprimento total $(\mathrm{cm})$ de plantas de crisântemo de acordo com o tamanho de recipiente e o substrato utilizado. Table 9. Total length $(\mathrm{cm})$ of chrysanthemum plant according to recipients size and substrate.

\begin{tabular}{|c|c|c|c|}
\hline \multirow{2}{*}{ Substrato } & \multicolumn{3}{|c|}{ Tamanho de recipiente } \\
\hline & Pequeno & Médio & Grande \\
\hline $\mathrm{S} 1^{\mathrm{a}}$ & 27,05 a B & $33,41 \mathrm{ab} \mathrm{AB}$ & 44,98 a $\mathrm{A}$ \\
\hline $\mathrm{S} 2^{\mathrm{a}}$ & 38,45 a $\mathrm{A}$ & 43,82 a A & 21,15 b B \\
\hline $\mathrm{S} 3^{\mathrm{a}}$ & 36,53 a $\mathrm{A}$ & $28,23 \mathrm{~b} \mathrm{~A}$ & $26,21 \mathrm{~b} \mathrm{~A}$ \\
\hline $\mathrm{S} 4^{\mathrm{a}}$ & 26,94 a A & $36,70 \mathrm{ab} \mathrm{A}$ & $28,41 \mathrm{~b} \mathrm{~A}$ \\
\hline CV $(\%)$ & \multicolumn{3}{|c|}{21,13} \\
\hline
\end{tabular}

${ }^{a}(\mathrm{~S} 1)$ Plantmax ${ }^{\circledR},(\mathrm{S} 2)$ Latossolo Vermelho + Areia + Cama de Frango 1 (1:1:1 v/v), (S3) Latossolo Vermelho + Areia + Cama de Frango 2 (1:1:1 v/v), (S4) Latossolo Vermelho + Areia + Cama de Frango $1+$ Cama de Frango 2 (1:1:1:1 v/v).

1 Médias com letras diferentes, minúscula na mesma coluna e maiúsculas na mesma linha, diferem significativamente ao nível de $5 \%$ de probabilidade pelo teste de Tukey.

Tabela 10. Massa de matéria seca $(\mathrm{g})$ de plantas de crisântemo de acordo com o tamanho de recipiente e o substrato utilizado.

Table 10. Mass dry matter (g) of chrysanthemum plant according to recipients size and substrate.

\begin{tabular}{|c|c|c|c|}
\hline \multirow{2}{*}{ Substrato } & \multicolumn{3}{|c|}{ Tamanho de recipiente } \\
\hline S1 ${ }^{\mathrm{a}}$ & Pequeno & Médio & Grande \\
\hline S2 ${ }^{\mathrm{a}}$ & $0,16 \mathrm{~b} \mathrm{~B}$ & $0,28 \mathrm{a} \mathrm{B}$ & $0,93 \mathrm{a} A$ \\
\hline S3 & $0,71 \mathrm{ab} \mathrm{A}$ & $0,75 \mathrm{a} \mathrm{A}$ & $0,20 \mathrm{~b} \mathrm{~A}$ \\
\hline S4 & $0,83 \mathrm{a} \mathrm{A}$ & $0,34 \mathrm{a} \mathrm{AB}$ & $0,15 \mathrm{~b} \mathrm{~B}$ \\
\hline $\mathrm{CV}(\%)$ & $0,21 \mathrm{ab} \mathrm{A}$ & $0,51 \mathrm{a} \mathrm{A}$ & $0,26 \mathrm{~b} \mathrm{~A}$ \\
\hline
\end{tabular}

${ }^{a}(\mathrm{~S} 1)$ Plantmax $^{\mathbb{}}$, (S2) Latossolo Vermelho + Areia + Cama de Frango 1 (1:1:1 v/v), (S3) Latossolo Vermelho + Areia + Cama de Frango 2 (1:1:1 v/v), (S4) Latossolo Vermelho + Areia + Cama de Frango $1+$ Cama de Frango 2 (1:1:1:1 v/v).

${ }^{1}$ Médias com letras diferentes, minúscula na mesma coluna e maiúsculas na mesma linha, diferem significativamente ao nível de $5 \%$ de probabilidade pelo teste de Tukey.

Os quatro substratos utilizados não diferem estatisticamente entre si, nos recipientes pequeno e médio para o comprimento total (Tabela 9) e massa da matéria seca das plantas (Tabela 10), respectivamente. Contudo, no recipiente grande, o substrato $\mathrm{S} 1$ foi superior para ambas as variáveis (Tabelas 9 e 10) quando comparado aos demais. Estes resultados podem estar ligados aos maiores valores de $\mathrm{P}, \mathrm{Ca}, \mathrm{Mg}$ e CTC deste substrato.

O CTC deste substrato é o único que está dentro da faixa considerada como ideal $\left(>12 \mathrm{cmolc} \mathrm{dm}^{-3}\right)$, por Penningsfeld (1983), para o cultivo de plantas em recipientes. A CTC de um substrato é a propriedade de suas partículas sólidas em adsorver e trocar cátions como $\mathrm{Ca}^{+2}, \mathrm{Mg}^{+2}, \mathrm{~K}^{+}, \mathrm{Na}^{+}$e $\mathrm{NH}_{4}^{+}$, desempenhando papel fundamental na reserva de nutrientes 
Tabela 11. Número de folhas, de plantas de crisântemo de acordo com o tamanho de recipiente e o substrato utilizado.

Table 11. Leaf number of chrysanthemum plant according to recipients size and substrate.

\begin{tabular}{|c|c|c|c|}
\hline \multirow{2}{*}{ Substrato } & \multicolumn{3}{|c|}{ Tamanho de recipiente } \\
\hline & Pequeno & Médio & Grande \\
\hline $\mathrm{S} 1^{\mathrm{a}}$ & $11,95 \mathrm{~b} \mathrm{~A}^{1}$ & 19,02 a $A$ & $13,02 \mathrm{ab} A$ \\
\hline $\mathrm{S} 2^{\mathrm{a}}$ & $13,61 \mathrm{ab} \mathrm{A}$ & 22,07 a A & 24,93 a A \\
\hline $\mathrm{S} 3^{\mathrm{a}}$ & $23,67 \mathrm{ab} \mathrm{A}$ & $20,81 \mathrm{a} A B$ & 9,60 b B \\
\hline $\mathrm{S} 4^{\mathrm{a}}$ & 28,120 a $\mathrm{A}$ & 14,35 a $\mathrm{AB}$ & $11,47 \mathrm{ab} B$ \\
\hline $\mathrm{CV}(\%)$ & \multicolumn{3}{|c|}{22,16} \\
\hline
\end{tabular}

${ }^{\mathrm{a}}$ (S1) Plantmax ${ }^{\circledR}$, (S2) Latossolo Vermelho + Areia + Cama de Frango 1 (1:1:1 v/v), (S3) Latossolo Vermelho + Areia + Cama de Frango 2 (1:1:1 v/v), (S4) Latossolo Vermelho + Areia + Cama de Frango $1+$ Cama de Frango $2(1: 1: 1: 1 \mathrm{v} / \mathrm{v})$.

${ }^{1}$ Médias com letras diferentes, minúscula na mesma coluna e maiúsculas na mesma linha, diferem significativamente ao nível de 5\% de probabilidade pelo teste de Tukey.

Tabela 12. Comprimento de raízes $(\mathrm{cm})$ de plantas de crisântemo de acordo com o tamanho de recipiente e o substrato utilizado.

Table 12. Roots lenght $(\mathrm{cm})$ of chrysanthemum plant according to recipients size and substrate.

\begin{tabular}{|cccc|}
\hline \multirow{2}{*}{ Substrato } & \multicolumn{3}{c}{ Tamanho de recipiente } \\
\cline { 2 - 4 } & Pequeno & Médio & Grande \\
\hline $\mathrm{S}^{\mathrm{a}}{ }^{\mathrm{a}}$ & $18,01 \mathrm{a} \mathrm{AB}^{1}$ & $23,58 \mathrm{ab} \mathrm{A}$ & $17,16 \mathrm{~b} \mathrm{~B}$ \\
$\mathrm{~S} 3^{\mathrm{a}}$ & $17,81 \mathrm{a} \mathrm{B}$ & $23,40 \mathrm{ab} \mathrm{AB}$ & $27,93 \mathrm{a} \mathrm{A}$ \\
$\mathrm{S}^{\mathrm{a}}$ & $21,98 \mathrm{a} \mathrm{A}$ & $26,86 \mathrm{a} \mathrm{A}$ & $13,95 \mathrm{~b} \mathrm{~B}$ \\
$\mathrm{CV}(\%)$ & $23,83 \mathrm{a} \mathrm{A}$ & $17,83 \mathrm{~b} \mathrm{AB}$ & $16,90 \mathrm{~b} \mathrm{~B}$ \\
\hline
\end{tabular}

${ }^{\mathrm{a}}(\mathrm{S} 1)$ Plantmax $^{\circledR},(\mathrm{S} 2)$ Latossolo Vermelho + Areia + Cama de Frango 1 (1:1:1 v/v), (S3) Latossolo Vermelho + Areia + Cama de Frango 2 (1:1:1 v/v), (S4) Latossolo Vermelho + Areia + Cama de Frango $1+$ Cama de Frango 2 (1:1:1:1 v/v).

${ }^{1}$ Médias com letras diferentes, minúscula na mesma coluna e maiúsculas na mesma linha, diferem significativamente ao nível de 5\% de probabilidade pelo teste de Tukey.

Tabela 13. Altura (cm), de plantas de crisântemo de acordo com o tamanho de recipiente e o substrato utilizado.

Table 13. Height plant (\%) of chrysanthemum plant according to recipients size and substrate.

\begin{tabular}{|c|c|c|c|}
\hline \multirow{2}{*}{ Substrato } & \multicolumn{3}{|c|}{ Tamanho de recipiente } \\
\hline & Pequeno & Médio & Grande \\
\hline $\mathrm{S} 1^{\mathrm{a}}$ & 8,92 a $^{1}$ & 13,12 a $\mathrm{A}$ & $11,25 \mathrm{ab} A$ \\
\hline $\mathrm{S} 2^{\mathrm{a}}$ & 9,23 a $\mathrm{A}$ & 10,00 a $\mathrm{A}$ & 17,05 a $\mathrm{A}$ \\
\hline $\mathrm{S} 3^{\mathrm{a}}$ & 16,46 a $\mathrm{A}$ & 16,95 a $A$ & $7,20 \mathrm{~b} \mathrm{~B}$ \\
\hline $\mathrm{S} 4^{\mathrm{a}}$ & 12,70 a $\mathrm{A}$ & 10,40 a $\mathrm{A}$ & $9,31 \mathrm{ab} A$ \\
\hline CV (\%) & & 38 & \\
\hline
\end{tabular}

${ }^{\mathrm{a}}(\mathrm{S} 1)$ Plantmax $^{\circledR}$, (S2) Latossolo Vermelho + Areia + Cama de Frango 1 (1:1:1 v/v), (S3) Latossolo Vermelho + Areia + Cama de Frango 2 (1:1:1 v/v), (S4) Latossolo Vermelho + Areia + Cama de Frango 1 + Cama de Frango 2 (1:1:1:1 v/v).

${ }^{1}$ Médias com letras diferentes, minúscula na mesma coluna e maiúsculas na mesma linha, diferem significativamente ao nível de $5 \%$ de probabilidade pelo teste de Tukey.

para as plantas. Além do CTC, o valor pH do substrato S1, também é o único que está na faixa considerada como ótima para substratos de base orgânica (KÄMPF, 2000), por isso de tal superioridade no presente trabalho com o S1 para comprimento total e massa da matéria seca das plantas.

Para o recipiente médio o maior comprimento total das plantas foi obtido com S2, seguido por S4 e S1. Estes substratos apresentaram os maiores valores de $\mathrm{P}$ em sua composição química. De acordo com Black (1967), o P é o elemento chave na fase inicial de crescimento devido ao maior acúmulo de biomassa nesta fase.

Nos substratos S4 e S3, as plantas em desenvolvimento nos recipientes testados não apresentaram diferença estatística para o comprimento total. O mesmo fato foi observado quando se comparou as médias de massa de matéria seca das plantas nos substratos S2 e S4 utilizandose os três recipientes, onde não apresentaram diferença estatística. No substrato S1, as maiores médias de massa de matéria seca (Tabela 10) e comprimento total das plantas (Tabela 9) foram obtidas no recipiente grande, sendo que, para esta última variável, a média assemelhouse estatisticamente do recipiente médio. Bezerra (2003) descreveu que recipientes maiores permitem maior volume de raízes, aumentando-se a área de absorção de nutrientes. Supõe-se que isto, aliado as características químicas e físicas deste substrato (Tabela 1 e 2), influenciou para 
maior desenvolvimento das plantas, principalmente do sistema radicular.

Por outro lado, nos substratos S2 e S3 houve as maiores médias para o comprimento total e massa da matéria seca utilizando-se os recipientes pequeno e médio (Tabelas 9 e 10).

O maior comprimento total obtido com os recipientes pequenos e médios no substrato $\mathrm{S} 2$ foram influenciados pela altura das plantas (Tabela 13), uma vez que o comprimento de raízes (Tabela 12) apresentou superioridade com o recipiente grande seguido pelo de tamanho médio.

Para o número de folhas, os substratos S1 e S2 não apresentaram diferenças estatísticas entre os recipientes, fato não obtido para S3 e S4, que tiveram as maiores médias com os recipientes pequeno e médio (Tabela 11), o que conforme já ressaltado para amor-perfeito ser vantajoso para economia do viveirista.

Isso foi ressaltado por Carneiro (1995), que afirmou que recipientes menores demandam menos volume de substrato, o que diminui a área ocupada no viveiro e os custos de transporte.

Entretanto, considerando-se cada recipiente houve as maiores médias para o número de folhas utilizandose o recipiente pequeno com os substratos S4, S3 e S2 (Tabela 11).

Acredita-se que o maior número de folhas com uso do recipiente pequeno e substratos $\mathrm{S} 2, \mathrm{~S} 3$ e $\mathrm{S} 4$ favoreceram para o maior acúmulo de massa de matéria seca, já que quanto mais folhas as plantas tiverem, maiores as chances de se produzir biomassa, uma vez que aumenta-se a taxa fotossintética e consequentemente mais fontes de carbono, necessários para o desenvolvimento das plantas. Contudo, o mesmo não ocorreu com o uso do recipiente grande, uma vez que as maiores médias foram verificadas com o substrato S2 seguido por S1 e S4. Dentro do recipiente de tamanho médio, os valores quantificados para o número de folhas não diferiram significativamente entre os substratos.

Em relação ao desenvolvimento radicular houve as maiores médias para $\mathrm{S} 3, \mathrm{~S} 1$ e $\mathrm{S} 4$ com os recipientes médio e pequeno (Tabela 12). O mesmo não ocorreu com o substrato $\mathrm{S} 2$ que teve os maiores resultados com o recipiente grande, seguido pelo médio, demonstrando que cada recipiente exerce influência diferenciada sobre o desenvolvimento radicular das plantas, de acordo com o substrato adotado.

Para altura das plantas, quando se utilizou o recipiente grande, o substrato $\mathrm{S} 2$ foi o que apresentou a maior média, porém este não diferiu do S1 e S4 (Tabela 13). Por outro lado, os recipientes pequeno e médio não apresentaram diferenças estatísticas de acordo com o substrato utilizado.

\section{CONCLUSÃO}

Para germinação e desenvolvimento inicial de amorperfeito o melhor recipiente foi o pequeno com a mistura Latossolo Vermelho + Areia + Cama de Frango 1 + Cama de frango $2(1: 1: 1: 1 \mathrm{v} / \mathrm{v})$. Para crisântemo além deste recipiente e mistura, também se destacaram as misturas Latossolo Vermelho + Areia + Cama de Frango 1 (1:1:1 v/v) e Latossolo Vermelho + Areia + Cama de Frango 2 $(1: 1: 1 \mathrm{v} / \mathrm{v})$

\section{REFERÊNCIAS}

BEZERRA, F.C. Produção de mudas de hortaliças em ambiente protegido. Fortaleza: Embrapa Agroindústria Tropical, 2003. 22p.

BLACK, C.A. Soil plant relationships. 2.ed. New York: J. Wiley, 1967. 792p.

CARNEIRO, J.G.A. Produção e controle de qualidade de mudas florestais. Curitiba: UFPR/FUPEF; Campos: UENF, 1995. 451p.

CARRIJO, O.A.; VIDAL, M.C.; REIS, N.V.B.; SOUZA, R.B.; NAKISHIMA, N.P. Produtividade de tomateiro em diferentes substratos e modelos de casa-de-vegetação. Horticultura Brasileira. v.22, n.1, p.5-9, 2004.

CARVALHO, G.R.; PIO, R.; PASQUAL, M. Influência de diferentes substratos na aclimatização de brotações de cafeeiro produzidos in vitro. Revista Unimar Ciências. v.9, n.1, p.69-73, 2000.

CASAGRANDE JÚNIOR, J.G.; VOLTOLINI, J.A.; HOFFMANN, A.; FACHINELLO, J.C. Efeito de materiais orgânicos no crescimento de mudas de araçazeiro (Psidium cattleyanum Sabine). Revista Brasileira de Agrociência. v.2, n.3, p.187-191, 1996.

CHAGAS, E.A.; FRÁGUAS, C.B.; SILVA, E.F.; PASQUAL, M.; MENDONÇA, V. Multiplicação in vitro de crisântemo cv. White Polaris. Revista Brasileira de Agrociência. v.10, n.1, p.123-126, 2006.

DEMARCHI, C. Guerra das flores movimenta os trópicos. Gazeta Mercantil Latino-Americana, s.1., 28 fev.04 mar. p.7-8, 2001.

FRANCISCO, M.G.S.; MARUYAMA, W.I.; MENDONÇA, V.; SILVA, E.A.; REIS, L.L.; LEAL, S.T. Substratos e recipientes na produção de mudas de mamoeiro 'Sunrise Solo'. Agrarian, v.3, n.9, p.267-274, 2010.

GUERRERO, F.; POLO, A. Control de las propriedades hidrofísicas de las turbas para su utilización agrícola. Agricoltura Mediterranea, v.119, p.453-459. 1989.

JUNQUEIRA, A.H.; PEETZ, M.S. Os pólos de produção de flores e plantas ornamentais do Brasil: uma análise do potencial exportador. Revista Brasileira de Horticultura Ornamental, Campinas, v.8, n.1/2, p. 25-47, 2002.

KÄMPF, A.N. Seleção de materiais para uso como substratos. In: KÄMPF, A.N.; FERMINO, M.H. (Ed.). Substratos para plantas: a base da produção vegetal em recipientes. Porto Alegre: Gênesis, p.139-145, 2000. 
LUZ, J.M.Q.; MORAIS, T.P.S.; BLANK, A.F.; SODRÉ, A.C.B.; GUEDMILLER, S. Teor, rendimento e composição química do óleo essencial de manjericão sob doses de cama de frango. Horticultura Brasileira, v.27, n.3, p.349-353, 2009 .

MATTOS, W.T.; MONTEIRO, F.A. Resposta de Braquiaria brizantha a doses de Potássio. Scientia Agricola. v.55, n.3, p.428-437, 1998.

NICOLOSO, F.T.; FORTUNATO, R.P.; ZANCHETTI, F.; CASSOL, L.F.; EISINGER, S.M. Recipientes e substratos na produção de mudas. Ciência Rural. v.30, n.6, p.987992, 2000

PASQUAL, M.; CHALFUN, N.N.J.; RAMOS, J.D.; VALE, M.R.; SILVA, C.R.R. Propagação de plantas frutíferas. Lavras:UFLA. 2001. 137 p.

PENNINGSFELD, F. Kultursubstrate fur den gartenbau, besonders in Deutschland: ein kritischer Überblick. Plant and Soil, The Hague, v.75, p.269-281, 1983.

PILLA, M.A.C.; HABER, L.L.; GRASSI FILHO, H. Uso racional de nutrientes no cultivo hidropônico de amorperfeito. Irriga. v.11, n.3, p.367-375, 2006.

SERRANO, L.A.L. Sistema de blocos prensados e doses de adubo de liberação lenta na formação de porta-enxerto cítrico. Ciência Rural, v.36, n.2, p.441-447, 2006.
TAIZ, L.; ZEIGER, E. Fisiologia Vegetal. 3 ed. Porto Alegre. Artmed. 2004, 719p.

WAGNER JÚNIOR, A.; ALEXANDRE, R.S.; NEGREIROS, J.R.S.; PIMENTEL, L.D.; SILVA, J.O.C.; BRUCKNER, C.H. Influência do substrato na germinação e desenvolvimento inicial de plantas de maracujazeiro amarelo (Passiflora edulis Sims f. flavicarpa Deg). Ciência e Agrotecnologia, Lavras, v.30, n.4, p.643-647, 2006a.

WAGNER JÚNIOR, A.; NERES, C.R.L.; NEGREIROS, J.R.S.; ALEXANDRE, R.S.; DINIZ, E.R.; PIMENTEL, L.D.; BRUCKNER, C.H. Substratos na formação de mudas de pinheira (Annona squamosa L.). Revista Ceres. v.53, n.308 p.439-445, 2006 b.

WAGNER JÚNIOR,A.; SANTOS, C.E.M.;ALEXANDRE, R.S.; SILVA, J.O.C.; NEGREIROS, J.R.S.; PIMENTEL, L.D.; ÁLVARES, V.S.; BRUCKNER, C.H. Efeito da préembebição das sementes e do substrato na germinação e no desenvolvimento inicial do maracujazeiro doce. Revista Ceres. v.54, n.311, p.1-6, 2007.

ZONTA, E.P.; MACHADO, A.A. Sanest - Sistema de Análise Estatística para Microcomputadores. Pelotas: UFPel, 1984. 75p. 
